N91-28195

\title{
NASA'S ADVANCED SPACE TRANSPORTATION SYSTEM LAUNCH VEHICLES
}

\author{
Darrell R. Branscome \\ Director, Advanced Program Development Division, \\ National Aeronautics and Space Administration
}




\title{
NASA'S ADVANCED SPACE TRANSPORTATION SYSTEM LAUNCH VEHICLES
}

\author{
Darrell R. Branscome \\ Director, Advanced Program Development Division, \\ Office of Space Flight \\ National Aeronautics and Space Administration \\ Washington, DC 20546
}

\begin{abstract}
On July 20, 1989, the 20th anniversary of the first Apollo-Lunar landing, President Bush outlined a long term national program for the Human Exploration of the Moon and Mars. Building upon the capabilities provided by Space Station Freedom, the President envisioned returning to the Moon and establishing a permanent manned station, to be followed by manned mission to Mars early in the next century. These are bold, new goals for the U.S. Space Program. They are, however, built upon a solid and pragmmatic base of planning. These demanding but realistic mission objectives, reflect the highest technical and enginering capabilities residing within the government and industrial capabilities of the industry.

This paper will provide some insight into the advanced transportation planning and systems that will evolve to support these long-term mission requirements. The general requirements include: launch and lift capacity to low earth orbit (LEO); space-based transfer systems for orbital operations between LEO and geosynchronous equatorial orbit (GEO), the Moon, and Mars; and transfer vehicle systems for long duration deepspace probes. These mission requirements are incorporated in the NASA Civil Needs Data Base. To accomplish these mission goals, adequate lift capacity to LEO must be available: to support science and application missions, to provide for construction of the Space Station Freedom and to support resupply of personnel and supplies for its operations. Growth in lift capacity must be time-phased to support an expanding mission model that includes Freedom Station, the "Mission To Planet Earth", and an expanded robotic planetary program. Near term launch vehicle system improvements will capitalize on the existing hardware and infrastructure of the Shuttle.
\end{abstract}

The near term increase in cargo lift capacity associated with development of the Shuttle-C vehicle will be addressed. The joint DODNASA 
Advanced Launch System studies are focused on a longer term new cargo capability that will significantly reduce costs of placing payloads in space.

Longer term transportation studies include the Next Manned Transportation System, and Space Transfer Vehicles. The Next Manned Transportation System studies are focused on concepts 10 extend, complement, or replace the Shuttle after the tum of the century. The next manned transportation system assessment is focussed on three distinctly different paths: Shuttle Evolution, a new Personnel Launch System, or an Advanced Manned Launch System. Space Transfer Vehicle studies to satisfy robotic and human exploration missions also have been initiated.

Activation of Space Station Freedom in the mid-90's connotes continuous human habitation with increasing crew complements and activities over time. If an accident were to occur, or if a major medical emergency were to arise, there must be an assured crew retum capability. NASA has initiated a program to address and evaluate the vehicle options and systems implications associated with providing this capability. Several contracied Assured Crew Return Vehicle concepts are under study and will be described.

All of these transportation vehicle activities are inter-related, and timephased to provide a comprehensive planning base for decisions related to future elements of national space transportation cafabilities. These programs provide broad options in terms of technology, cost, and development risk, and in terms of fleet size, lift capacity, and mission operational flexibility. When combined with companion studies on missions and experiments, a complete set of program options will be available for defining the course of the United States civil space program.

\section{Lotreduction}

President Bush, during the 20th Anniversary of the First Manned Landing on the Moon cermonies, recognizing that the Space Shuttle has returned to flight and that the development of the international Space Station Freedom is now underway, established a long term national goal for the United States to lead a program directed to the Human Exploration of the Moon and Mars. These missions are the realization of mission planners "dreams" from the earliest days of the U.S. Space Program. While these mission are extremely challenging and will demand the ultimate in engineering and science capabilities and skills, they are achievable and are, in fact, the culmination of planning and study activities that have been underway for over six years in anticipation of these decisions. 
During this period the United States has substantially altered the proposed content of our future National Space Program. These changes began in 1984 with President Reagan's "State of the Union" announcement of the decision to establish a permanent manned presence in space using an international space station'. Also during 1984, at the direction of the United States Congress, the National Commission on Space, was formed to review the $U$. S. space program, to recommend long range goals, and to define a roadmap for the next fifty years. In their report, published in May 1986, Pioneering The Space Frontier, the Commission recommended an orderly, step-by-step program, based on a broad expansion and development of low cost institutions and operating systems, which would ultimately lead to the exploration of the solar system and habitation of the Moon and Mars'2.

The Commission's plan for low cost access to the inner solar system has been replicated as Figure 1. The first section, Highway to Space, outlines the transportation requirements to Earth orbit and for orbital operations. Cargo and passenger transport vehicles are identified as well as transfer vehicles having the ability to base at Space Station Freedom. The second section, Bridge Between Worlds, identifies expansion of operations beyond Earth orbit. Large transfer vehicles are envisioned, operating between Earth's orbit and the lunar and Mars orbits, followed by surface operations and extended surface habitation.

Subsequent to the Commission's Report, the NASA Administrator formed a study team, chaired by Astronaut Sally Ride, to define an implementation plan for the achievement of a national space policy directed toward an expanded human presence in space. The Ride report to the NASA Administrator, Leadership and America's Fuiure in Space ${ }^{3}$, recommended four major mission elements::

- Mission To Planet Earth

- Exploration of the Solar System

- Outpost on the Moon

- Humans to Mars

The report provided a roadmap for the President Bush's Human Exploration Initiative and is the framework for detailed long range NASA planning activities. 


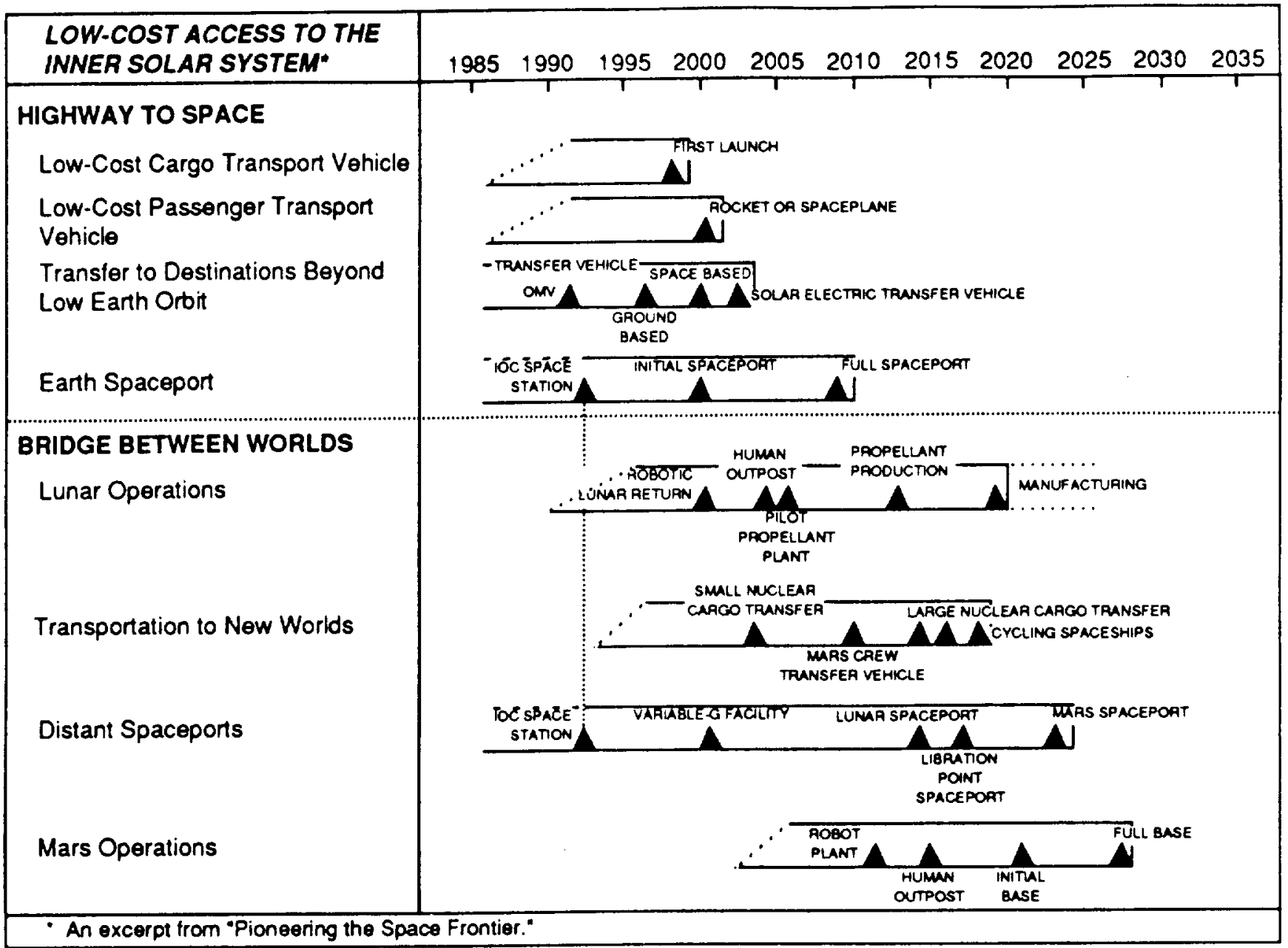

Figure 1. Low-Cost Access to the Inner Solar System. 


\section{Backereund}

Both civilian and military space program plans were affected by national space policy decisions that occurred during the 1980's. To map out an orderly and balanced plan for the United States to follow, the Joint NASA/DOD National Space Transportation Support Study (NSTSS) was initiated. This study program, often referenced as the Space Transportation Architecture Study (STAS), established overall space transportation needs and defined timeframes when these capabilities would be required. As outlined in Table 1, the STAS Study Team recommended that five major capabilities be phased in by 2005 . The requirement for a cargo return vehicle has been satisfied by modification of the Shutle to provide increased downweight and landing capability. The recent LDEF recovery of approximately 22,000 lbs.was a record for landed Shuttle weights. A requirement to provide for an Assured Crew Return Capability (ACRC) from Space Station Freedom was subsequently added by NASA advisory bodies.

\section{Mission Requirements Definition}

For the remainder of the century, the United States' civil programs will rely in large part on the Shuttle to transport all personnel and most large payloads to orbit. Major mission requirements, as summarized in Table 2, illusirate the significant increases in launch demand over time. Near-term launch requirements are dominated by the delivery of science and solar system exploration spacecraft, Spacelab, and a variety of DOD payloads. In the period from the mid-1990's through 2000 , the assembly, activation, and crew exchange for Space Station Freedom and launch of the Earth Orbiting System-Polar Orbiting Platforms significantly increase launch requirements. Beyond the turn of the century, sustaining crew rotation and logistic suppon of Space Station Freedom operations, science observatories, robotic planetary explorers, and human exploration initiatives will require additional transportation capabilities.

In order to match the wide variety of payload manifesting requirements to projected launch capacity and schedules, NASA has developed the Civil Needs Data Base (CNDB). The CNDB provides insight into the total annual mass to be delivered and the numbers of payloads that will require delivery to specific orbital locations. The CNDB is revised annually to project all future civil mission requirements ${ }^{4}$. Two models are developed within the CNDB as illustrated in Figure 2; a base model, and an expanded model reflecting increasing levels of program activity. 
Table 1

\section{SUMMARY OF NATIONAL SPACE TRANSPORTATION SUPPORT STUDY RECOMMENDATIONS}

\section{SUMMARY OF NSTSS STUDY TEAM RECOMMENDATIONS}

IIME FRAME

- Cargo Vehicle / Heavy Llfit - DERNATIVE VEHICLE - NEW VEHICLE

Mid 1990 's

$-2000$

- NexI Manned Space Transportation System 2005

- New High Energy Upper Stage

$-2000$

- Cargo Return Vehlcle Mid-1990's

Table 2

\section{MISSION REQUIREMENTS (SUMMARY)}

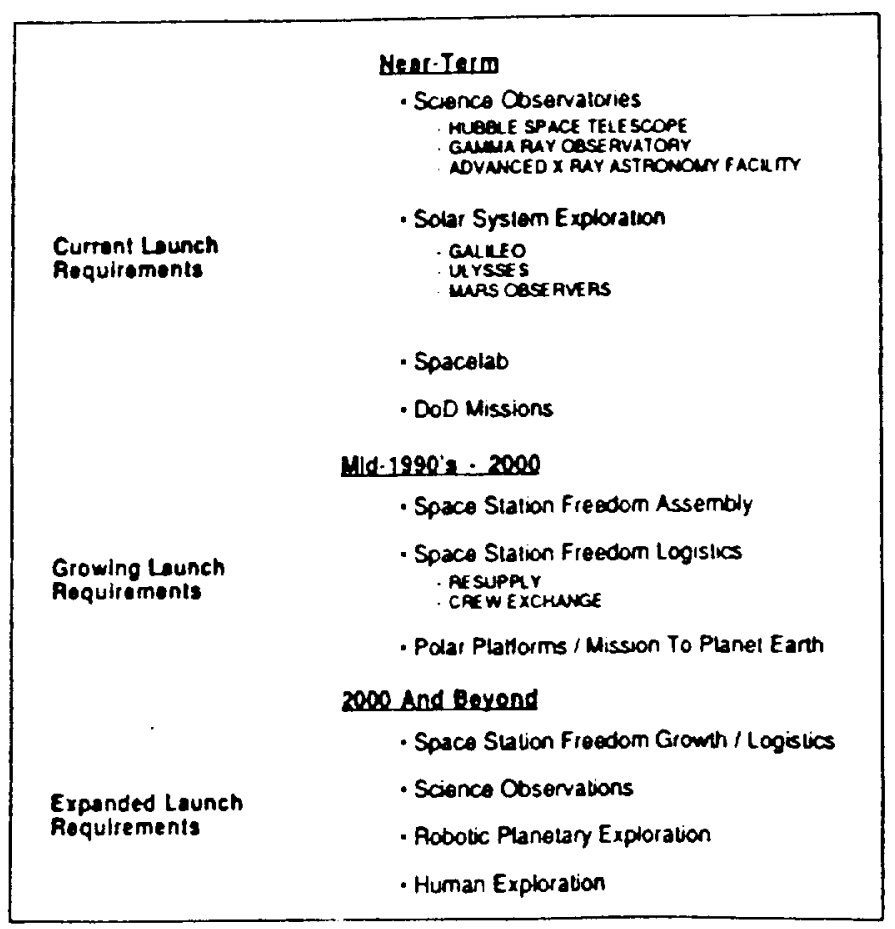




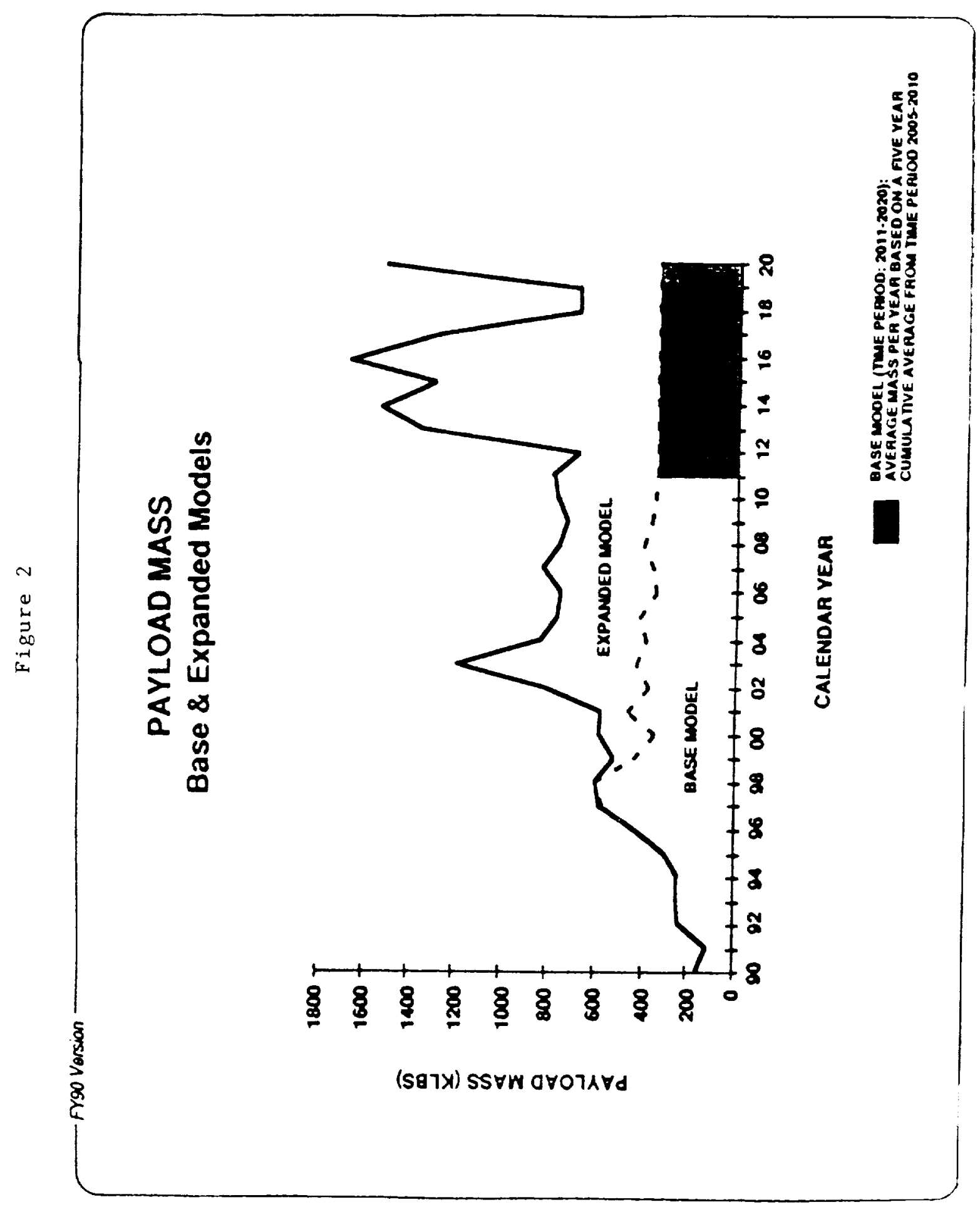


The base model is developed by summing the seecific mission needs of each current NASA Program Office. These include misions contained in the NASA Mixed Fleet Mainifest, all Space Station Freedom assembly/ construction, crew rotation and logistic support, Mission to Planet Earth and the deep space program launches.

The expanded model includes projected requirements and includes launch mass additions for conversion of the Space Station Freedom from a microgravity facility to a transportation node, the deep space science payloads with high-energy stages required for the unmanned precursor missions to the planets, and the Lunar and Mars human exploration mission now being conceptualized by the Office of Exploration in NASA. Significant total mass increases of the expanded model over the base model after the turn of the century are apparent.

A detailed review of the expanded model also clearly illustrates projected differences in future launch vehicle requirements from capabilities currently available in the Shuttle and ELV's. As shown in Figure 3, hardware and propellant launch requirements for the manned Lunar and Mars missions after the turn of the century literally overwhelm all of the other requirements for Space Station buildup. Space Station logistics, and the planetary precursor missions, immediately. These are the data necessary for planning and sizing the future US launch vehicle fleet

\section{Carge Vehicle Definition Studies}

The United States has a clear and evolving need for increased lift capacity to deliver both large masses and large volumes to LEO. Mission requirements in the CNDB indicate that a large, unmanned, cargo launch vehicle is necessary and could satisfy a "niche" in the total launch vehicle inventory later in this decade and into the next Century. Development of unmanned cargo vehicles with payloads in the range of $100 \mathrm{~K}-300 \mathrm{~K}$ pounds to LEO, using either existing assets or new technology, would be extremely cost effective. Increases in the cargo payload per launch could be applied to reduce the total number of launches required and to reduce and simplify the orbital assembly operations mandated by small, multiple units of structure. Larger structural units, tanks, and fuel supplies for energetic planetary missions could be delivered in fewer flights. Two large cargo vehicle concepts are being explored. Either one can provide the United States with a wide range of payload mass and volume options.

The unmanned Shuttle-C launch vehicle concept, which makes use of existing Shuttle elements and infrastructure, could be available in the mid1990's. In Shuttle-C, shown in Figure 4, the Orbiter would be replaced 
Figure 3

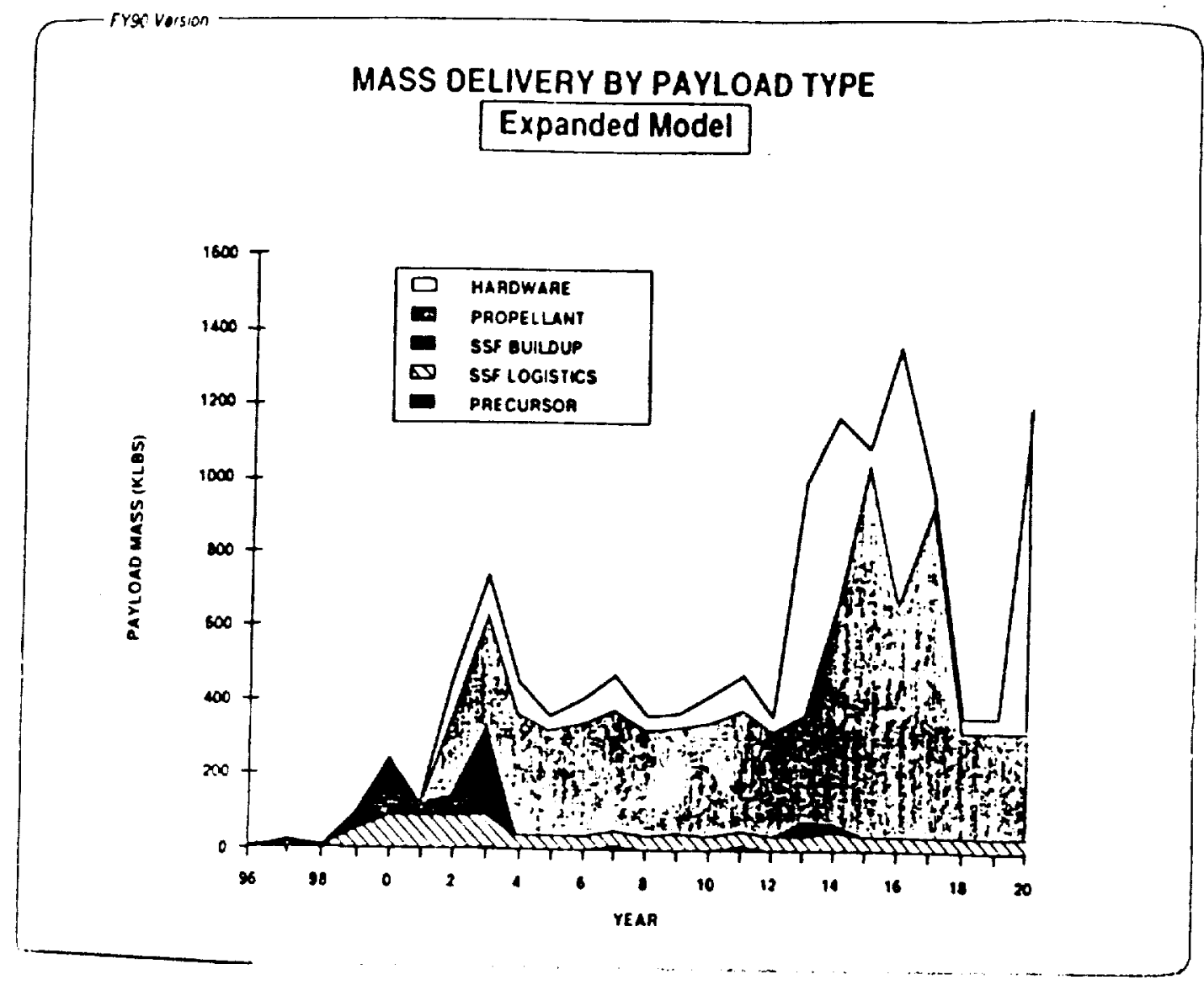




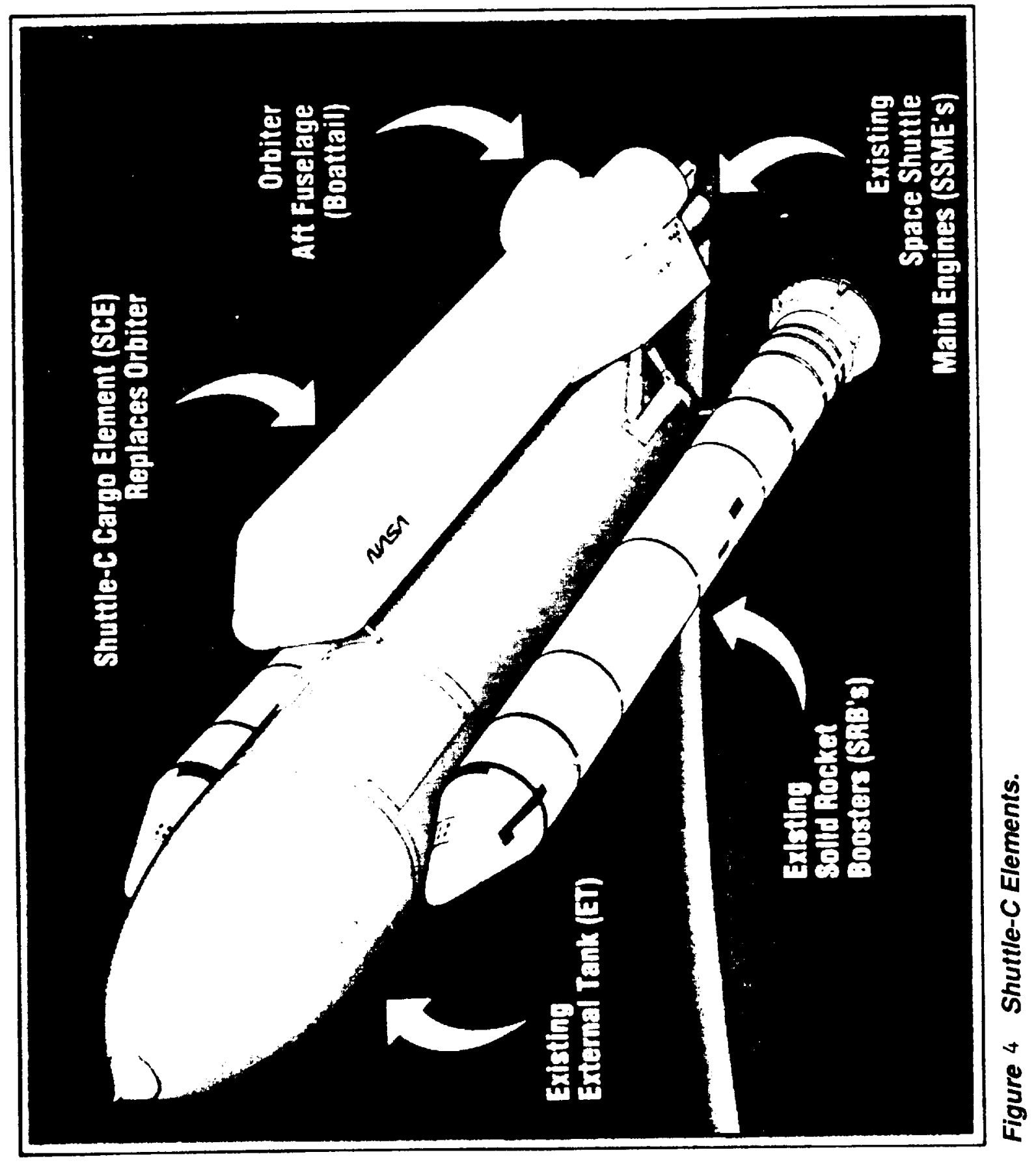


with a large cargo carrier element mounted in the same location. This new cargo element design is illustrated in the full sized Engineering Model at the Marshall Space Flight Center (Figure 5) and has an aerodynamic nose fairing on the forebody and a modified and simplified orbiter afterbody with three Space Shutle Main Engines. The payload is mounted internally under full length split doors which open for deployment at LEO injection altitude. On completion of the operation, the cargo element structure including the engines reenters the atmosphere. The Shuttle-C program schedule is shown in Figure 6 . Shuttle-C offers the potential for lifting $100 \mathrm{~K}-150 \mathrm{~K}$ pounds to orbit. Shuttle-C, operating concurrently with Shuttle and utilizing the same assembly and launch facilities at KSC, could satisfy many cargo requirements identified in the CNDB into the next Century. Because of the variety of large payloads and diverse requirements, developing from the detailed studies of the Human Exploration InitiativeManned Lunar and Mars Missions, various shroud sizes and configurations are now being evaluated including cryogenic oxygen and hydrogen propellani tankers.

A second cargo vehicle study is the joint DOD/NASA Advanced Launch System. (ALS) Program. The program has an initial operational capability (IOC) now planned for 200? as depicted in Figure 7. The goal of the ALS program is to minimize the cost per pound of payload delivered to LEO. The ALS concept emphasizes simplicity in design and operation, commonality in propellants, modularity in construction and assembly, a free-standing launch capability, separation of the launch vehicle and the payload interfaces, rapid turnaround, and very high system and mission reliability. The ALS is actually a "family" of vehicles, as shown in (Figure 8), which can be tailored to launch/payload/mission requirements by the addition or deletion of standardized "strap-on" elements. The ALS "family" would provide cargo lift capacity up to possibly $300 \mathrm{~K}$ pounds.

\section{Assured Crew Beturn Capabilits}

An Assured Crew Return Vehicle (ACRV) is necessary to provide return of crew from Space Station Freedom in the event of crew medical emergency, a Station Freedom emergency, or the STS being unavailable for an extended period of time. Artists renderings of four distinctly different ACRV concepts are illustrated in Figure 9. At the top left, a Station Crew Return Alternate Module (SCRAM) vehicle is shown; it is based on a simple, aerodynamically stable, seaworthy capsule concept. At the top right, a ballistic reentry configuration based on a Discoverer module is illustrated. Other ballistic concepts include the Apollo derived configuration shown on the lower left. These three are designed for a water landing. At the lower right, a mid-range Lift/Drag lifting-body configuration is shown. 


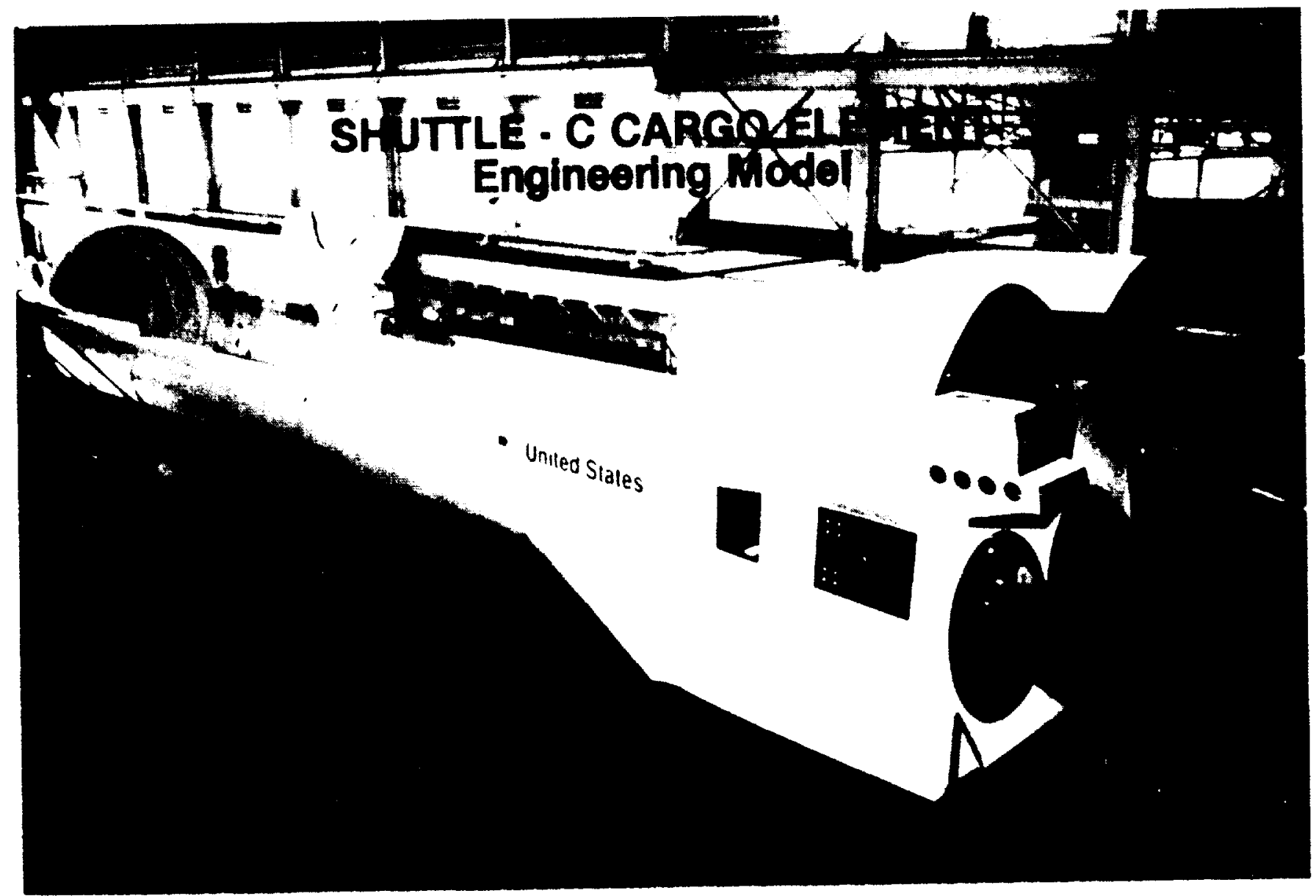

Figure 5. Shuttle C Engineering Model.

Figure 6

\section{SHUTTLE-C SCHEDULE}

RFP READY -

FY92 Proposed

"New Start" -

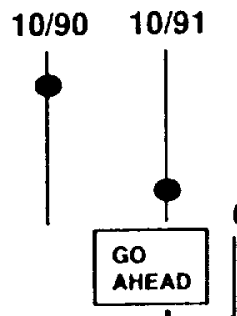

- PROPOSALS / EVALUATION -

- CONTRACT AWARD -

- FABRICATION \& ASSEMBLY -

- FIRST FLIGHT -

- SECOND FLIGHT -
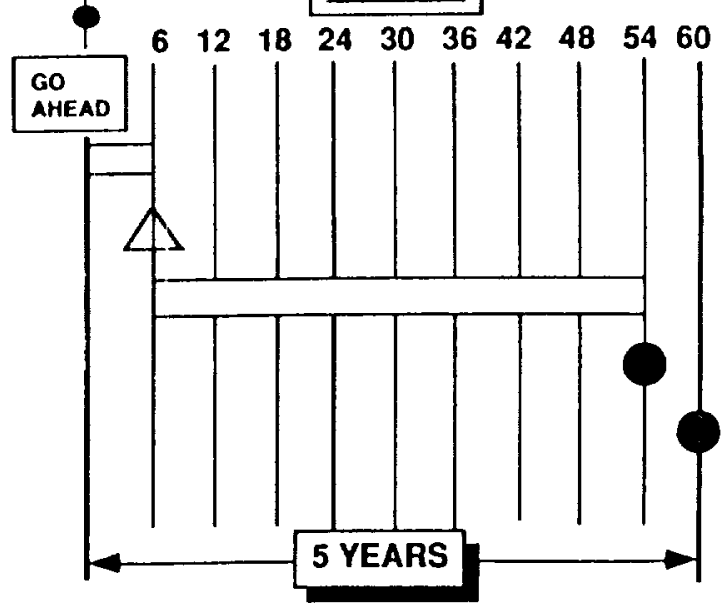
Figure 7

\section{ADVANCED LAUNCH SYSTEM (ALS) SCHEUULE}

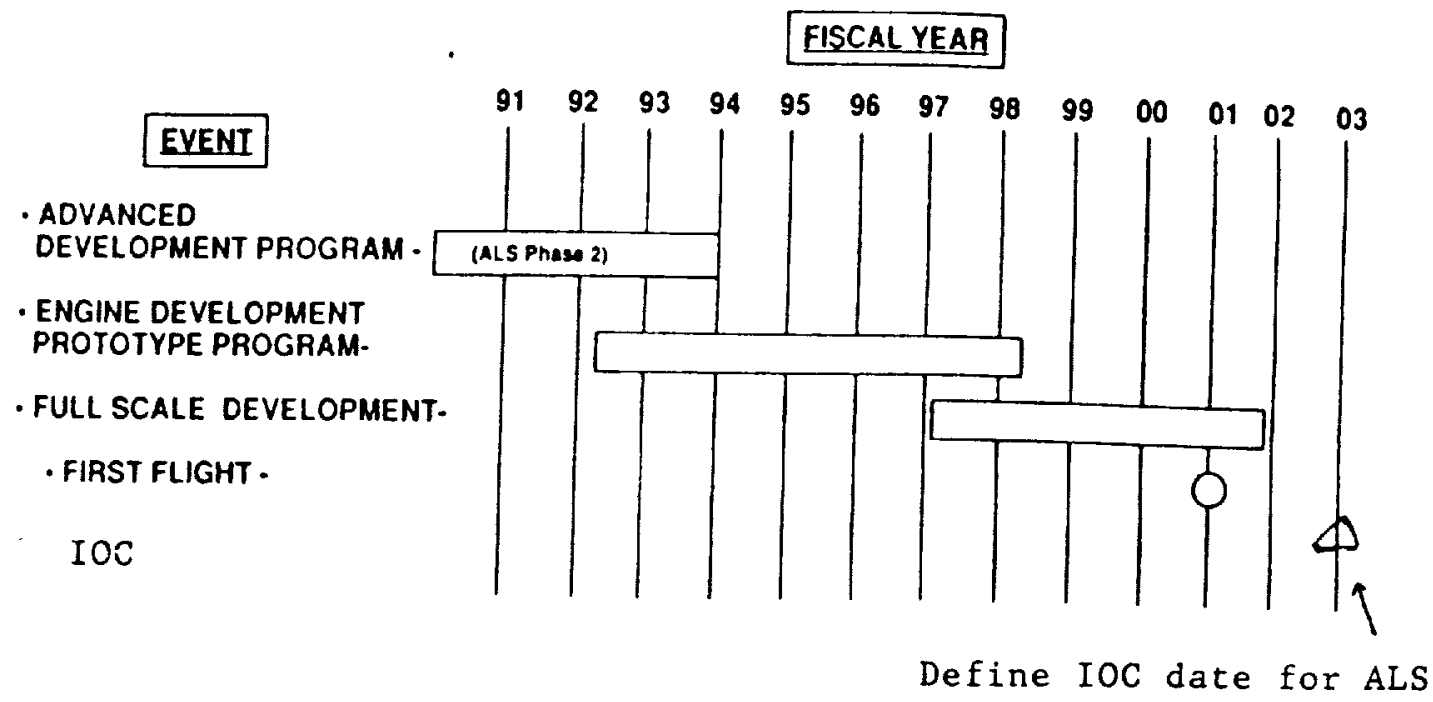

Figure 8

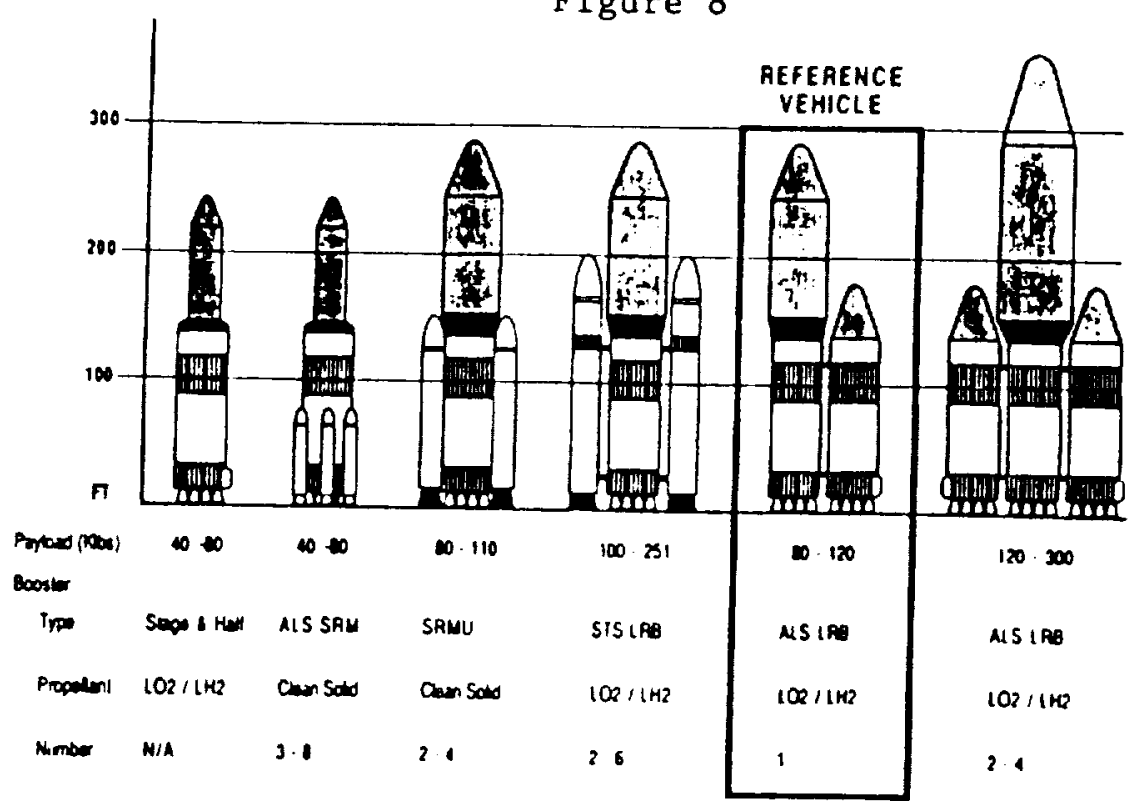




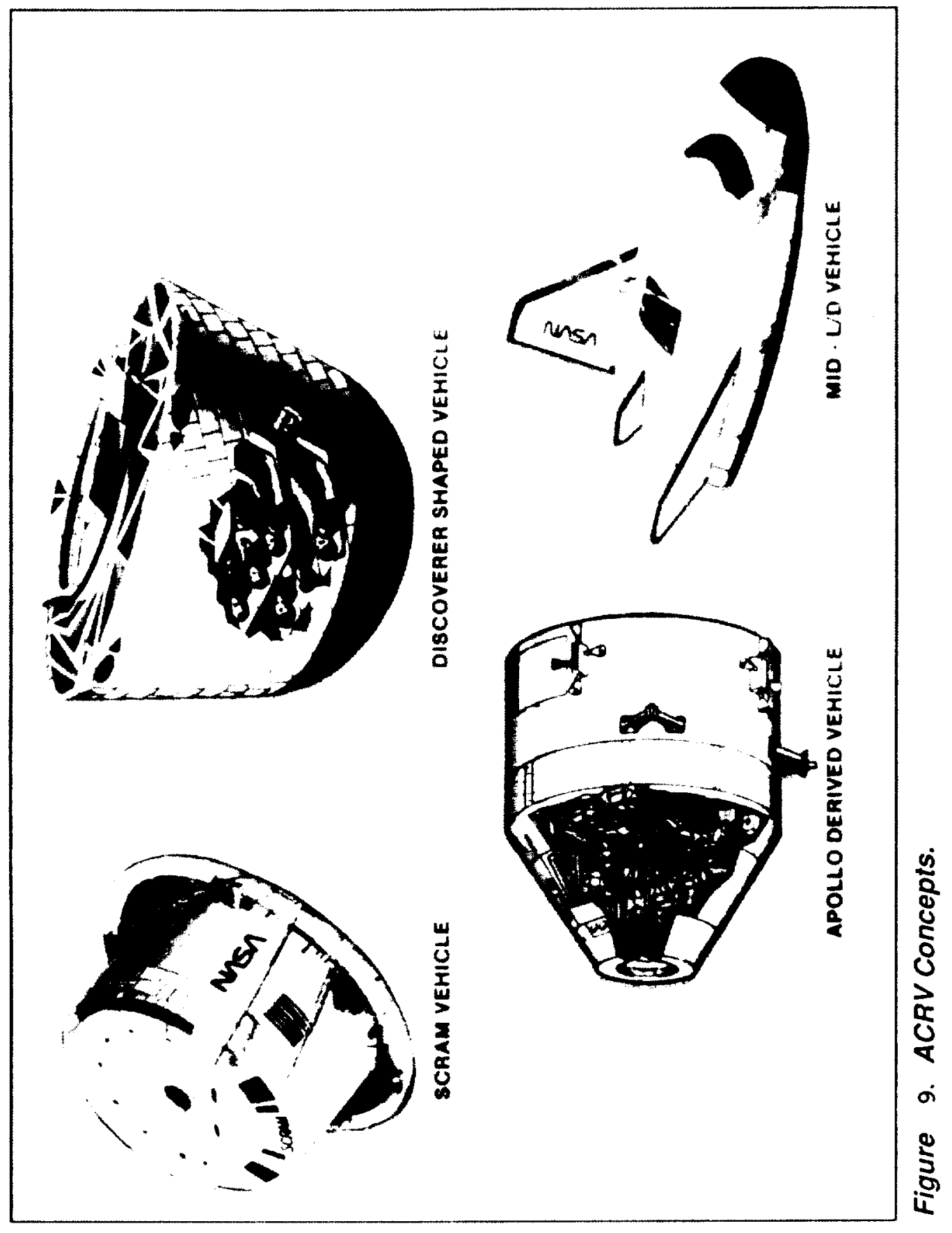


Competitive assessment of these divergent concepts/configurations including such considerations as crew size, recovery on water or land, and multiple use are under evaluation by two contractor teams.

ACRV in-house studies have been completed, and as shown in the schedule (Figure 10), two Phase A-Prime concept and systems definition study contracts are now underway. The teams, one consisting of Lockheed, Boeing and IBM, and the other consisting of Rockwell International, McDonnell-Douglas, TRW and Honeywell have been selected to perform the Phase A-Prime studies. Continuation of the Phase B activities, concentrating on a limited number of vehicle options are planned for the first quarter of FY91.

\section{The Next Manned Transportation System Definition Studies}

The existing demand for personnel transport and support of Space Station Freedom extends beyond the projected life span of the existing Shuttle orbiter fleet. Therefore, an integrated space transportation plan for the United States must consider the upgrading or replacement of our manned transportation system. The Shuttle design is now almost 20 years old; new technology is available for a greatly improved design with a significant improvement in performance and cost. The Shuttle was designed as a maximum performance system, is operated near its design limits in almost all areas, and has very little operational margin. The absence of design and operating margin drive the cost of operation and ownership of the Shuttle. The challenge is to define the Next Manned Transportation System (NMTS) design specifications 10 retain and possibly enhance reliability and safety, yet attain significantly reduced reduced life cycle cost.

The NMTS studies are directed to three very different approaches as shown in Figure 11: Shuttle Evolution, Personnel Launch System (PLS), and Advanced Manned Launch System (AMLS). Each approach offers unique design and operational features.

The first, Shuttle Evolution, conceptually illustrated in Figure 12, builds on the existing NSTS in an evolutionary, orderly, systematic program to provide specific improvements in performance, cost reductions, and enhanced reliability and safety. Changes could be incorporated in the existing fleet as modifications or retrofits, in the construction of new orbiter vehicles, or in a major redesign of any of the four major STS
elements. 


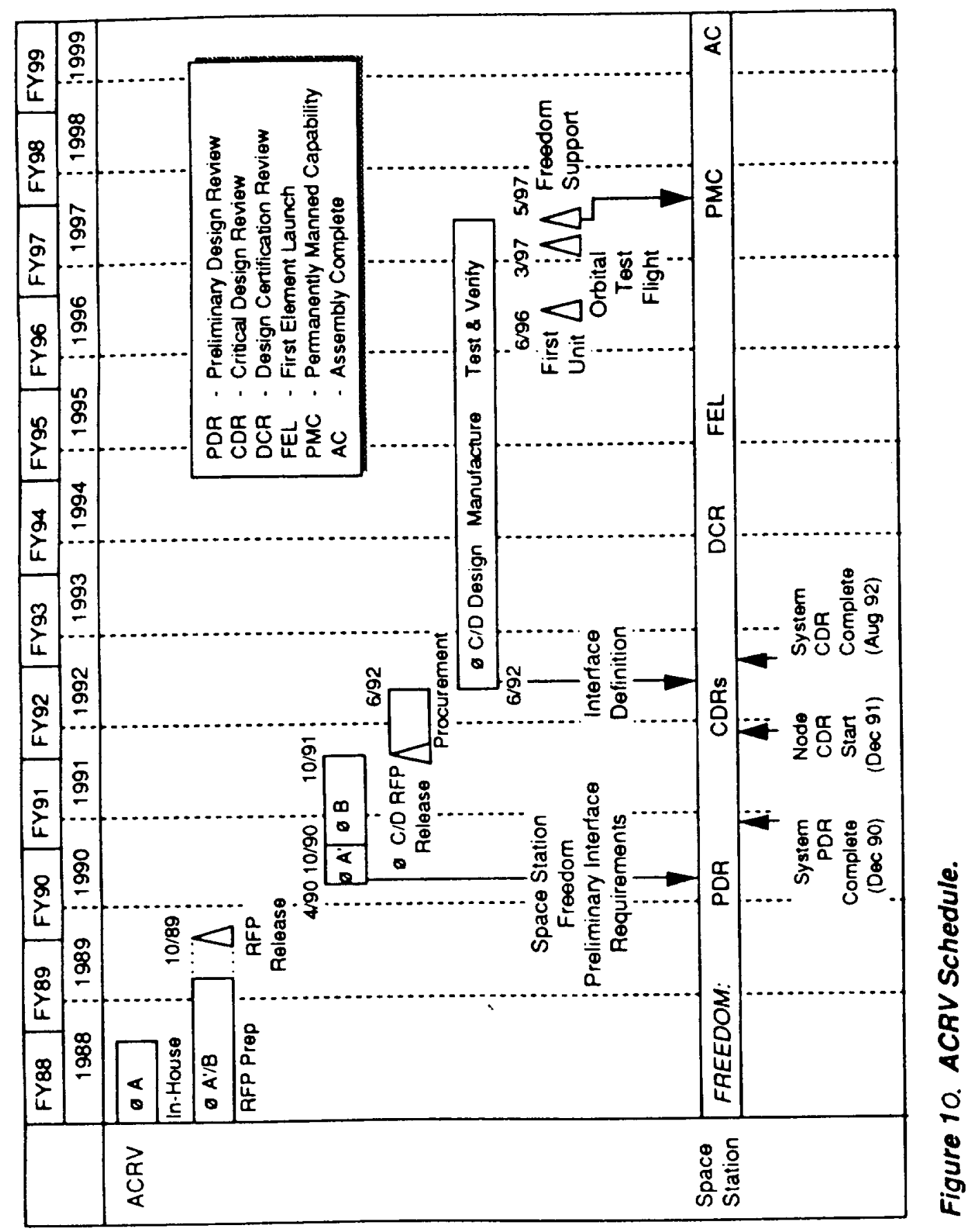


Figure 11

\section{NMTS CANDIDATE CONCEPTS}
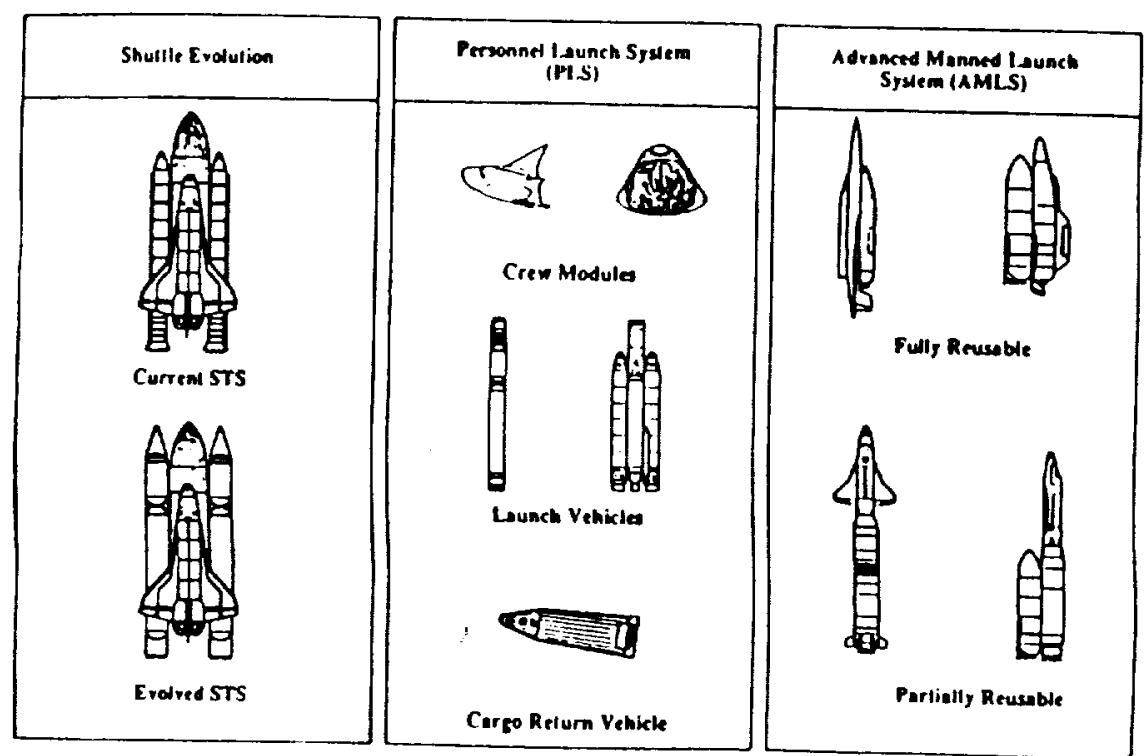

Figure 12

\section{nusn}
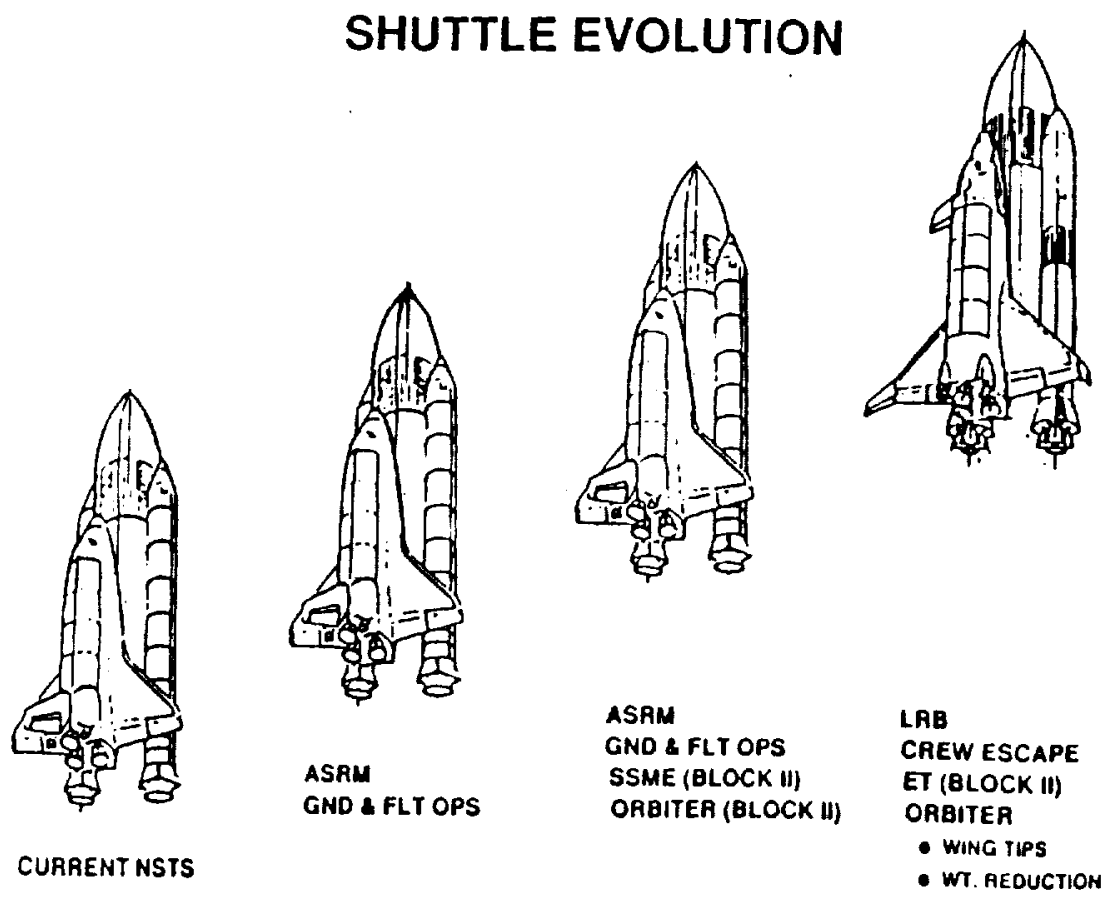

CURRENT NSTS

Ollice Of Space Flight 
The second, the NMTS option, considers concepts which constrain the vehicle to delivery and recovery of personnel only. This option, in effect, forces virtually all cargo delivery onto Shuttle or dedicated unmanned cargo vehicles. These concepts, shown as the Personnel Launch System (PLS) in Figure 13, have the smallest payload requirements. Two study contracts for the conceptual design of the spacecraft capable of uansporting a crew of up tolo, have been awarded. These studies are to explore whether a ballistic or a lifting body reentry configuration is the preferred concept. The Langley Research Center contract for the lifting body configuration, conceptually illustrated in Figure 14, was awarded to Rockwell Intemational Corp. The Johnson Space Center contract for assessment of a ballistic configuration, shown in a launch configuration in Figure 15, was awarded to the Boeing Co. These studies both address whether an existing (expendable) launch vehicle or a new launch vehicle is preferred.

The third option being considered in the NMTS assessment is the Advanced Manned Launch System (AMLS), which is a "clean sheet" advanced design to exploit new technologies that become arailable near the end of the decade. An AMLS, illustrated in Figure 16, is conceptualized as a two stage, rocket-powered, fully recoverable, manned, modular launch vehicle system incorporating advanced hypersonic aerodynamics, "hot" structures with advanced high temperature materials, and cryogenic propellants.

The NMTS asessments are now underway to support the NASA out-year budget and planning schedule. Conceptual design studies, followed by a downselection of concepts by the summer of 1991, will support agency decisions on the preferred approach.

\section{Soace Transfer Vehicle Definition}

NASA is assessing various configurations and design concepts for space transfer vehicles (STV) to deliver geosynchronous payloads, precursor robotic planetary exploration missions and evolution to support human exploration. A conceptualized STV is illustrated in Figure 17 as a reuseable, space-based, hydrogen/oxygen high performance stage with an aerobraker for either planetary or Earth orbit insertion. The STV would be configured to grow and evolve to provide increased performance capabilities as requirements expand, posssibly evolving from an initially unmanned to a man-rated capability.

The existing Centaur provides a very high level of performance and the RL-10 expander cycle engine is relatively simple and highly reliable. Study activitics are underway to explore the potential of upgrading and 


\section{SIMPLE RUGGED PEOPLE CARRIER PATH}

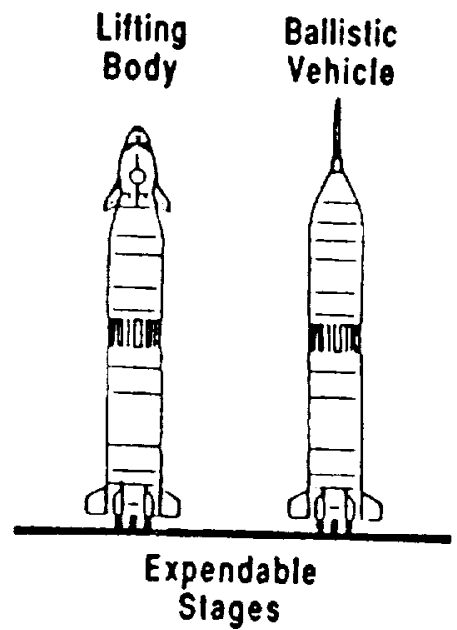

Figure 13

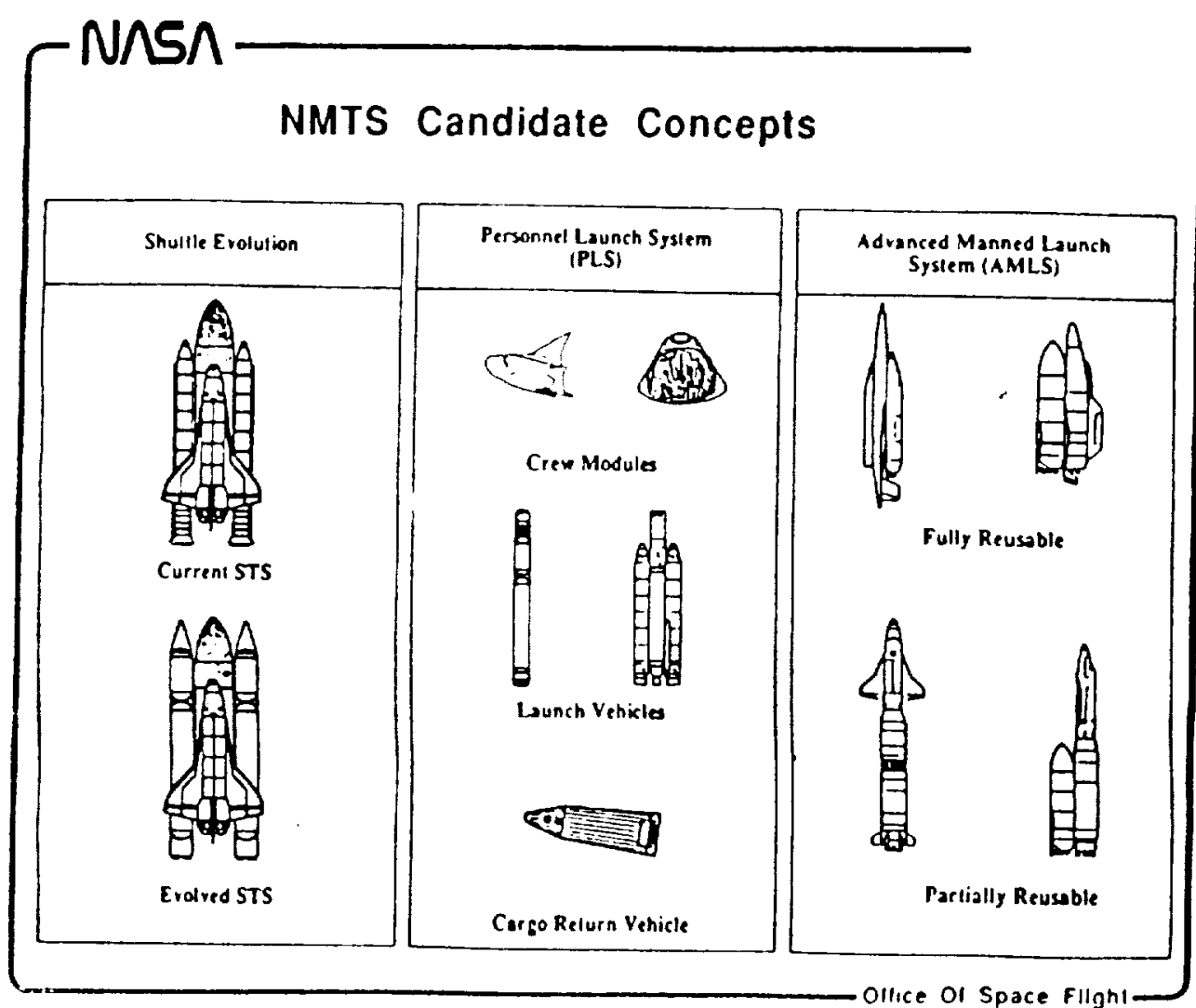


Figure 14

PLS Lifting Body Configuration

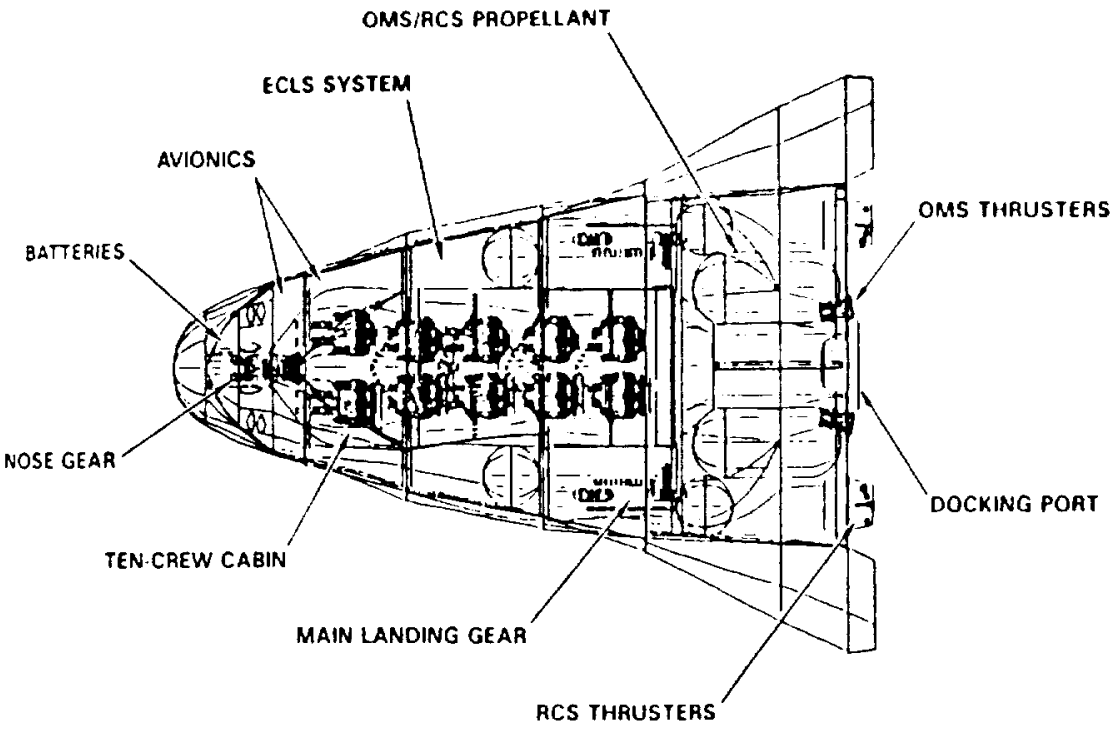

Figure 15

PLS Ballistic Configuration

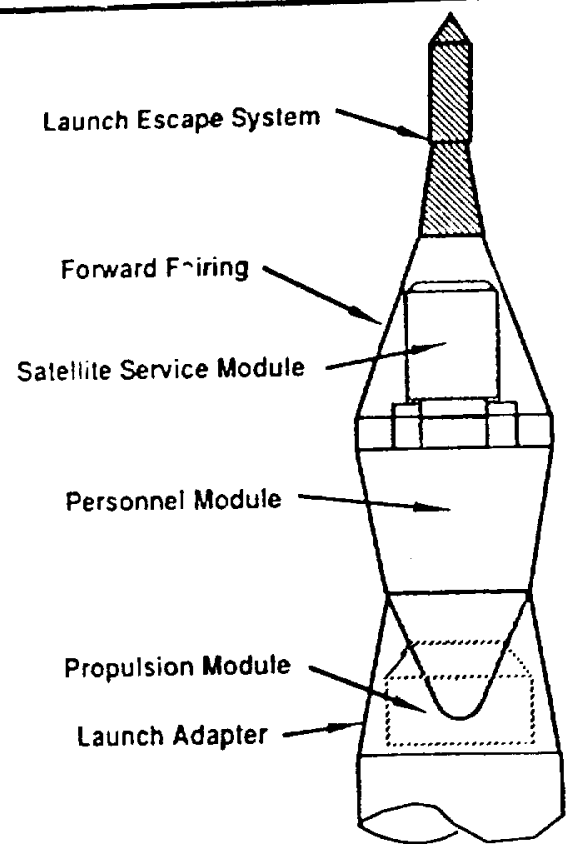

Point of Departure Configuration Rationale:

- Blconlc shape olters simplicliy In destgnas well as oxisting dalabase

- Inveried Posltion on Launch Vehicle:

- Single couch posltion for ascenl and descent accelerations, orbltal operalions, os well as nose-down water lending

- Prolectlon of TPS during pre-launch and escent.

- Expendable propulsion module locallan does not Intertere with docking / servicing tunctlons located on teeslde. 


\section{ADVANCED MANNED LAUNCH SYSTEM}

ROLE OF TECHNOLOGY

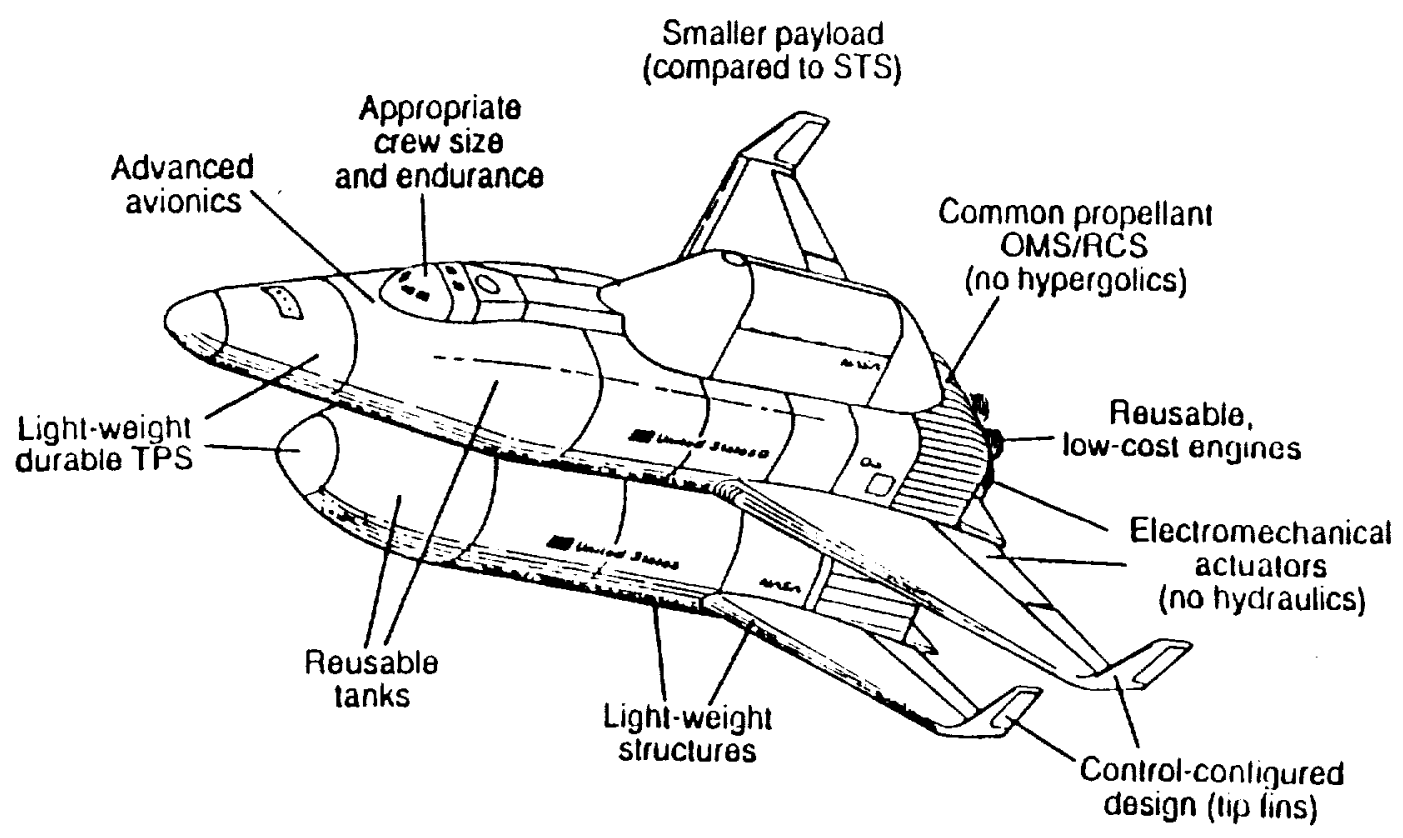

Office Of Space Flighi 


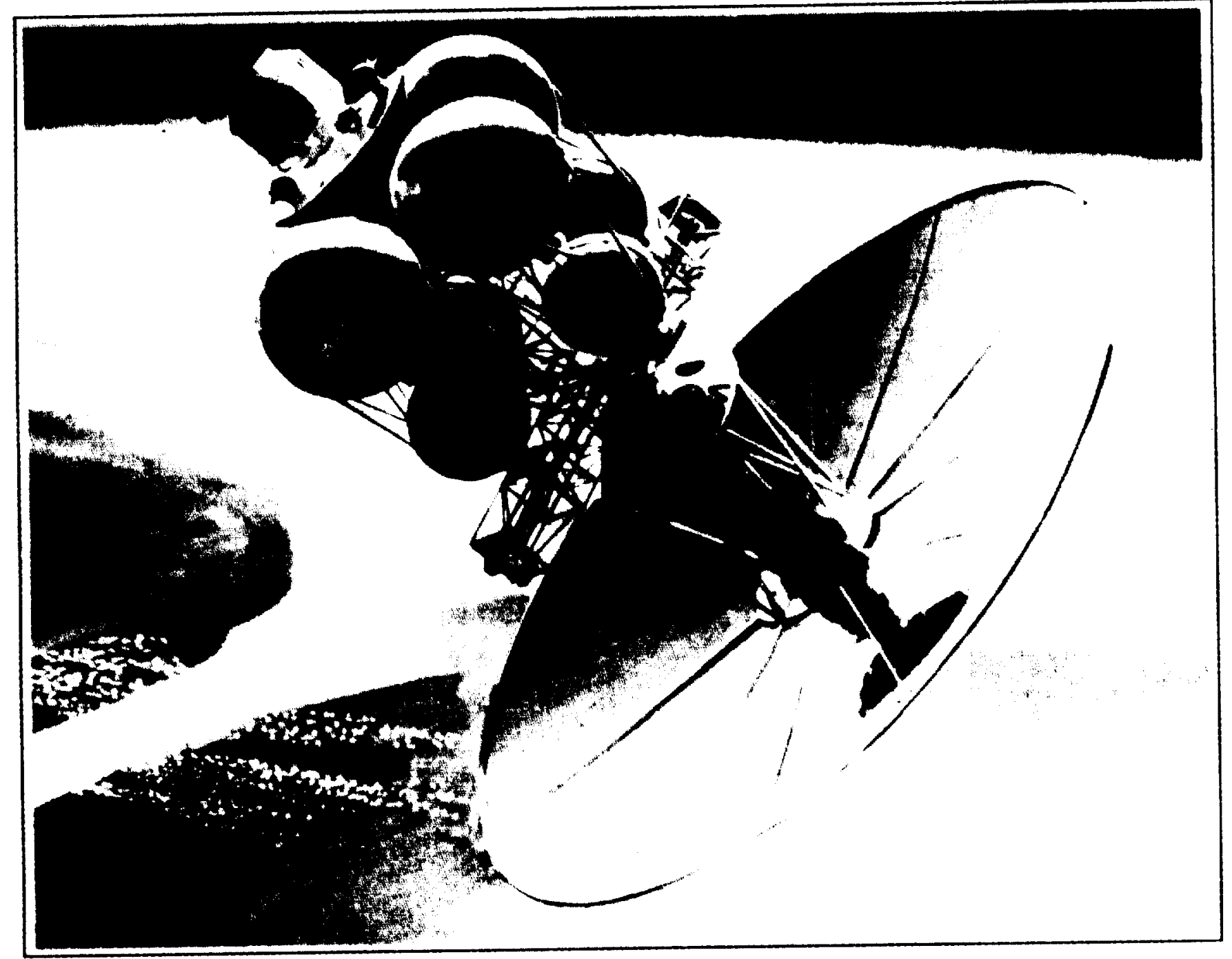

Figure 17. STV Configuration. 
re-configuring the Centaur (Figure 18) as an unmanned, near term interim upper stage/STV propulsion sub-system.

A concept for a recoverable STV, based on NASA in-house preliminary design studies, is illustrated in Figure 19. This concept incorporates an independently recoverable, 12,000 pound propulsion module. The empty tank set could be expended for increased flexibility in operations. Both expendable and recoverable concepts are being evaluated against various high-energy mission requirements. Technology drivers for the STV include aeroassist for atmospheric braking, a new higher performance cryogenic reuseable engine, and in-space cryogenic storage and transfer for reusability. Development and operational cost comparisons and cost prediction models are being developed. Design requirements are being identified for size, thrust levels and operational performance.

Eighteen month, Phase A STV Concept Definition study contracts were awarded to the Boeing Co. and Martin-Marietta Corp. in August of 1989.

\section{Summary}

The full flight capabilities of the Shuttle have been reestablished and we are preparing for the deployment of Space Station Freedom. NASA is committed to continuation of the deep space scientific missions and the Earth orbiting systems (EOs) to support "Mission to the Planet Earth. Major planning activities are underway to define the precursor robotic exploration of the solar system and the human exploration missions to the Moon and Mars. These mission planning activities are responsive to the National Goals established by President Bush, to recommendations from the National Commision on Space, to Dr. Rides' report to the Administrator, and to National Space Policy decisions. This guidance clearly defines and establishes major national mission requirements and presents the framework for the evaluation and assessment of long-term space transportation needs.

Long term mission and payload mass requirements have been inventoried in the CNDB. The CNDB provides a framework for the analysis of the launch vehicle requirements and the timeframes when specific launch vehicle and space transfer vehicle capabilities must be available.

System studies in each of the major vehicle classification have been initiated and are underway, each providing necessary information and detail for future decisions. Cargo vehicle studies for Shuttle-C and ALS, provide the increased unmanned lift capacity needed to support expansion of the deep space robotic missions, and the human exploration of the Moon and Mars. 


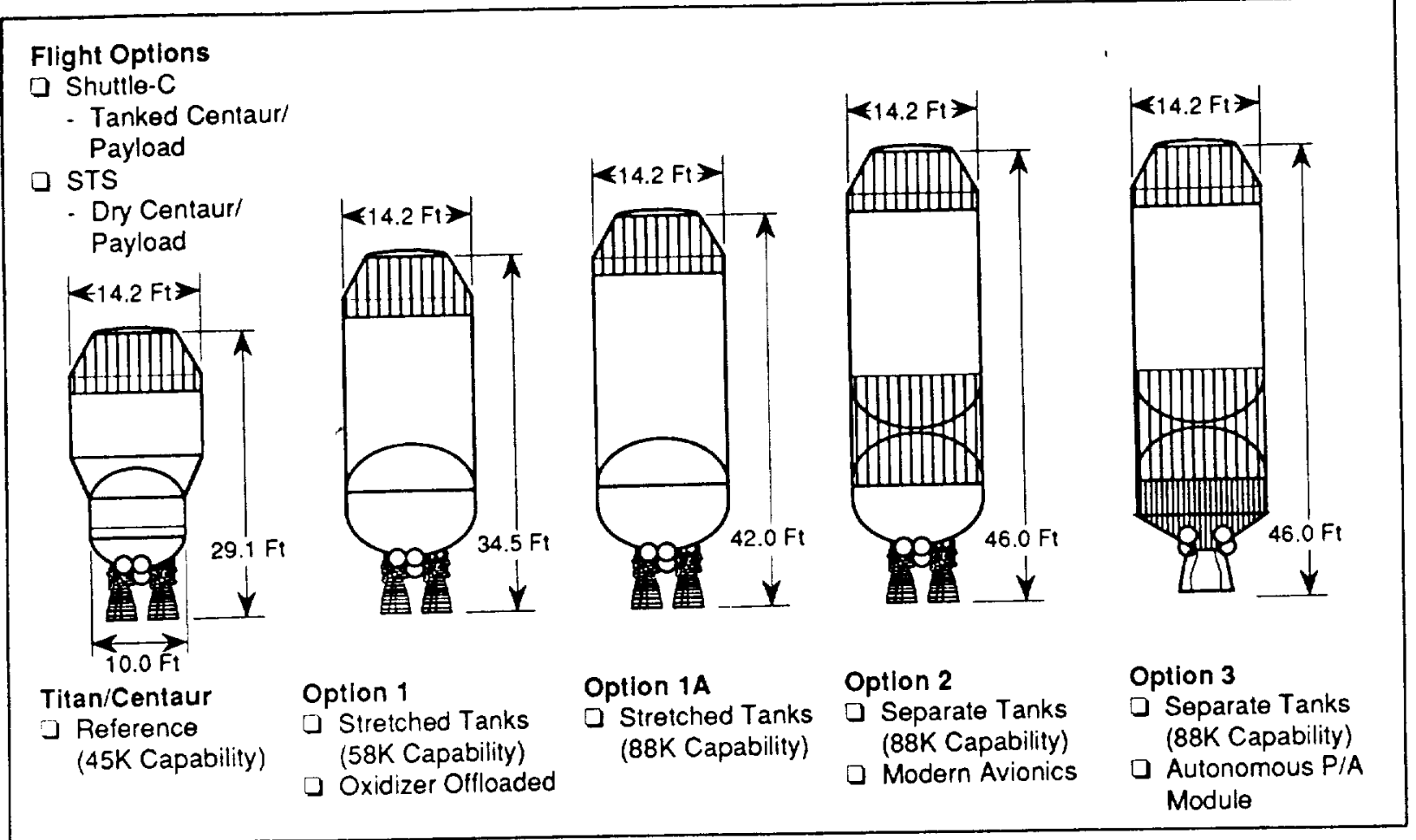

Figure 18. Centaur Upper Stage/STV Planning.

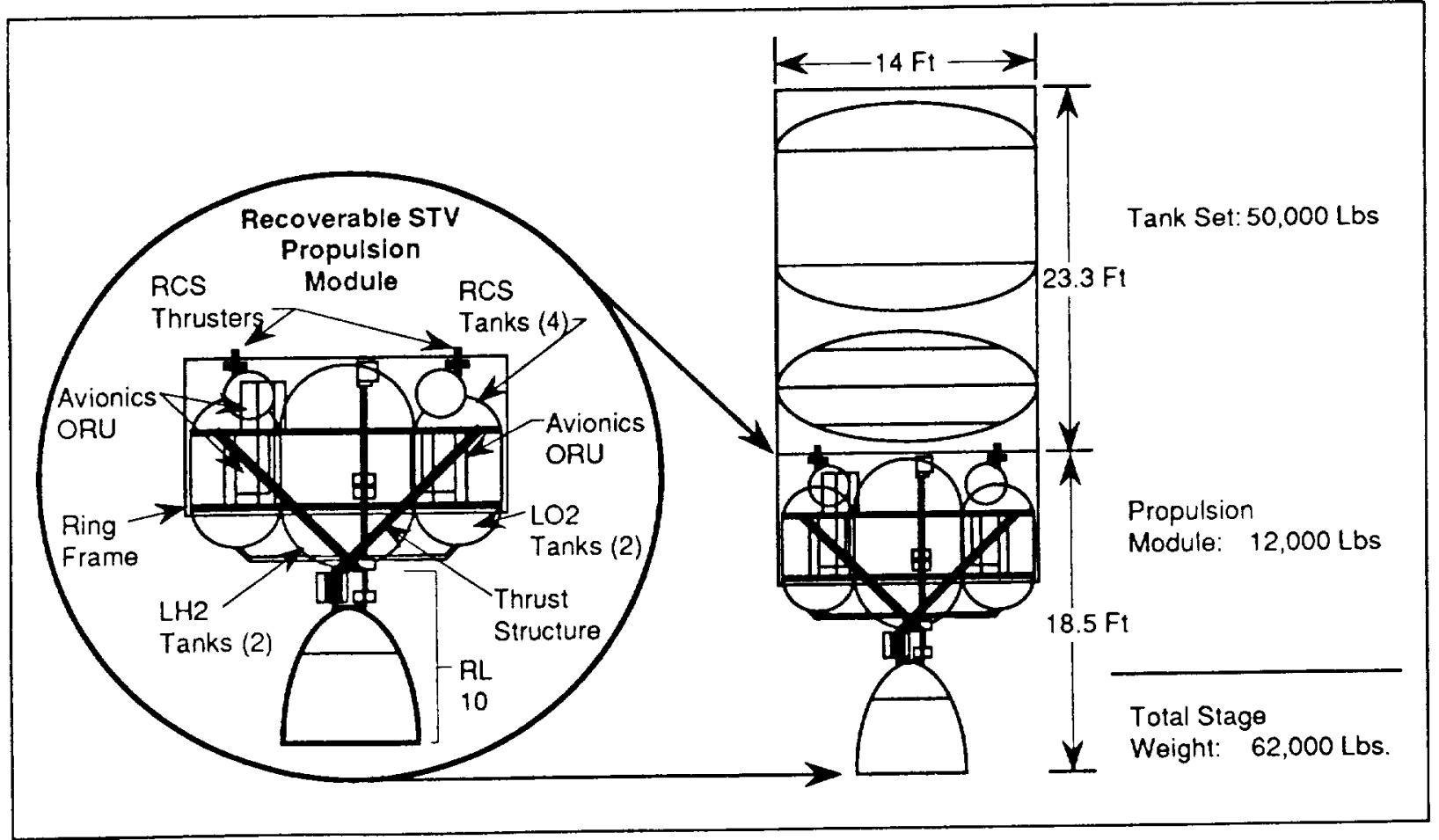

Figure 19. Recoverable STV Propulsion Concept. 
The NMTS studies are directed to the definition of options for manned night beyond the current Shuttle capabilities. Each of the three NMTS studies underway are unique: Shuttle Evolution adding technological improvements and building upon assets and capabilities inherent in the Shuttle, the PLS, directed exclusively to personnel/crew launch and recovery, and the AMLS representing a next generation capability based on advanced technology. These Next Manned Transportation System studies, are in support of the decision, (planned for 1992), on how the United States manned vehicle development program should proceed.

The ACRC studies are on a schedule to provide a necessary crew return capability for the Space Station Freedom-Permanently Manned Capability (PMC) in the summer of 1997.

The STV activities will define space-based, aerobraking, cryogenic, vehicle concepts that will permit multiple reuse from LEO and will evolve over time to support expanded unmanned and manned exploration missions. Space Station Freedom will function as a node for STV space-basing, onorbit servicing, and resupply.

A broad and diverse range of future requirements have been identified. Lead times for transportation systems are very long and future needs must be anticipated well in advance. The challenge is to satisfy these requirements, in a time phased sequence, to assure that both lift capacity and operational capabilities are available when needed. The studies and programs described are in place and are structured to support the definition of an integrated advanced transportation system for the United States. Over the next several years we must define an advanced transportation system that can sustain the evolutionary manned space flight program envisioned by the President and the American public. These systems will form the basis for a space transportation system that will satisfy projected mission and traffic demand well into the next century.

\section{Relerenses}

1. President Ronald Reagan, Space Station decision, State of the Union Message to a joint session of the U.S. Congress, January 24,1984

2 The National Commission on Space, "Pioneering the Space Frontier", Bantam Books. May 1986.

3. Ride, Dr. Sally K, Leadership and America's Future in Space, A Report to the NASA Administralor, Augusi 1987.

4. The NASA Civil Necds Dala Basc Updatc, FY90 Version, (Volumes?-?) March 23. 1990. 


\section{Figures (List -Interim titles)}

Figure 1. Low Cost Access to the Inner Solar System

Figure 2 (CNDB) Payload Mass, Base \& Expanded Models

Figure 3. Mass Delivery by Payload Type

Figure 4. Shuttle C Elements

Figure 5. Shuttle C Engineering Model

Figure 6. Shutle-C Schedule

Figure 7 ALS Schedule

Figure 8. ALS Family of Vehicles

Figure 9. ACRV Concepts

Figure 10. ACRV Schedule

Figure 11. NMTS, Candidate Concepts

Figure 12. Shuttle Evolution

Figure 13. PLS Concepts

Figure 14, PLS Lifting Body Configuration (Rockwell)

Figure 15. PLS Ballistic Configuration(Bocing)

Figure 16. AMLS Concept

Figure 17. STV Configuration

Figure 18. Centaur Upper Stage/STV Planning

Figure 19. Recoverable STV Propulsion Concept

Tables

Table 1. Summary of National Space Transportation Suppor Study Recommendations Table 2. Mission Requirements (Summary) 

PRESENTATION 1.1.3

MAINTAINING TECHNICAL EXCELLENCE 
